Research Article

\title{
Study on Ventilation System Linkage Control Strategy in a Double-Hole Tunnel Fire
}

\author{
Yizhou Zhuang $\mathbb{D}^{1},{ }^{1}$ Hao Ding $\mathbb{D},{ }^{1}$ Guoping Zheng $\mathbb{D}^{1},{ }^{1}$ Youkai Cui $\mathbb{D}{ }^{2}$ and Yan Huang $\mathbb{D}^{3}$ \\ ${ }^{1}$ College of Civil Engineering and Architecture, Zhejiang University of Technology, Hangzhou 310000, China \\ ${ }^{2}$ Zhejiang Provincial Institute of Communications, Planning, Design and Research, Hangzhou 310000, China \\ ${ }^{3}$ Consultant, Zhoushan, China \\ Correspondence should be addressed to Guoping Zheng; 20931180@qq.com
}

Received 31 January 2020; Revised 4 April 2020; Accepted 20 April 2020; Published 21 May 2020

Academic Editor: Sakar Mohan

Copyright (c) 2020 Yizhou Zhuang et al. This is an open access article distributed under the Creative Commons Attribution License, which permits unrestricted use, distribution, and reproduction in any medium, provided the original work is properly cited.

\begin{abstract}
In order to prevent smoke from flowing backward and penetrating into adjacent tunnel through cross channels during evacuation in case of fire accidents in highway tunnels, it is extremely necessary to implement the linkage control scheme for double-hole tunnel ventilation system. Therefore, six linkage control schemes for ventilation system are proposed in this article. Firstly, these six schemes were numerically simulated through Fire Dynamics Simulator (FDS) to obtain the flow velocity, flow direction, and smoke distribution under different schemes when the peak power of fire accidents is $30 \mathrm{MW}$. And two better schemes were selected for further investigation based on the evacuation conditions in the upper stream of fire source. Secondly, a $1: 10$ scale model experiment was conducted to test these two schemes, and the results from numerical simulation and model experiment were compared and verified. Finally, the location of fire accident, the time to develop stable opposite airflow, and the number of open cross channels were analyzed to confirm the applicability of the recommended scheme. The results show that the optimal scheme is to switch on the fans in the upstream of the fire accident and the fans on both sides of the cross channel in the non-fire tunnel to form positive pressure to control the smoke flow. This scheme ensures a stable and uniform smoke flow in the cross channel and personnel's safety during evacuation.
\end{abstract}

\section{Introduction}

Fire accident is the riskiest factor for operating highway tunnels [1]. In 1999, 38 people died in a fire in the Mont Blanc Tunnel connecting Italy and France. In 2006, six people died in a fire at the Viamala Tunnel on Switzerland's A13 Highway. In 2007, three people died in a tunnel fire the on US Interstate No. 5. In recent years, there is an increasing number of long tunnels in China. As of 2017, there were 16, 229 highway tunnels in the Chinese mainland, including 902 extra-long tunnels and 3,841 long tunnels. And more than 110 extra-long tunnels over $5 \mathrm{~km}$ are expected to be built in the next 10 years. Meanwhile, fire accidents in highway tunnels in China are also increasing. A bus spontaneously ignited in Wuxi Huishan Tunnel in 2010 and killed 24 people. In 2014, in Yanhou Tunnel of Jinji Expressway in
Jincheng in Shanxi Province, a methanol tanker rear-ended another one, causing a fire accident and killing 40 people. A kindergarten shuttle bus spontaneously ignited in Taojiakuang Tunnel in Shandong Weihai in 2017 and killed 13 people. In the same year, in Futuyu No. 5 Tunnel of Zhangshi Expressway in Hebei Province, a gas tanker explosion ignited 5 coal trucks, resulting in 12 deaths. According to incomplete statistics, more than 90 people have been killed in highway tunnel fires in China since 2010.

Longitudinal ventilation and smoke exhaust mode is widely used in highway tunnels because it is cost-effective, simple to operate and manage, and effective in preventing smoke from flowing backward. And the transverse evacuation mode is usually adopted in a double-hole tunnel to effectively evacuate people in the upper stream of fire during fire accidents. It is generally believed that people 
downstream of a fire can leave the tunnel quickly by vehicles, but it is difficult for people upstream of a fire to evacuate quickly from the entrance and exit of the tunnel, so they need to be evacuated from a cross channel to neighboring non-fire tunnel. Therefore, in order to prevent smoke from flowing backward and penetrating into neighboring tunnel which may cause a secondary disaster, it is important to formulate a reasonable linkage control strategy of ventilation system in a double-hole tunnel.

At present, a lot of researches have been conducted on tunnel fires, especially tunnel smoke control, at home and abroad. Since 2001, a lot of systematic research projects about tunnel fire have been performed in Europe, such as EUREKA EU 499, FIT, DARTS, Safe Tunnel, Sirtaki, Virtual Fires, UPTUN, Safe-T, EUROTAP, L-SURF, EGSISTES, and SOLIT [2-4]. Among them, the comprehensive large-scale research on fire accident carried out by Swedish, Dutch and Norwegian research institutes in the abandoned Ruhamar tunnel in 2003 is famous [5]. In 2005, Peng et al. [6] carried out 10 full-scale tests in three highway tunnels in Yunnan Province. In 2010, Zhejiang Provincial Institute of Communications, Planning, Design \& Research and Zhongnan University $[11,12]$ developed a 1:10 fire smoke exhaust model test and a 1:1 component test for three extra-long tunnels in Zhejiang Province. In 2015, Xu et al. [7] made a full-scale (cross-sectional) model according to the Hong Kong-Zhuhai-Macao Bridge Immersed Tunnel to test the smoke flow and temperature. In 2017, Guo et al. [8] carried out full-scale tests on the characteristics of fire smoke and temperature fields in high-altitude tunnels. In 2018, Cao et al. [9] studied the flow of lateral centralized smoke exhaust by a full-scale test based on the Hong Kong-Zhuhai-Macao Bridge Immersed Tunnel. In the same year, Chen et al. [10] studied the performance of the low-pressure water mist fire extinguishing by a full-scale model test in Qincaitang Tunnel 1 of Anchu Highway in Yunnan Province. Many other studies have been carried out through scale model tests $[13,14]$, fire dynamics numerical analysis software (such as CFD and FDS) [15-19] and theoretical analysis [20].

Most studies focus on a single tunnel, and there were few studies about the ventilation system of a double-hole tunnel. Wang et al. [21] studied the ventilation of extra-long highway tunnel during fire accidents through network ventilation theory. Zeng et al. [22-24] studied the ventilation schemes for many highway tunnels through network ventilation. Tarada [25] put forward the idea of calculating critical velocity in cross channels, and suggested that the minimum flow velocity in cross channels of Young Don Railway Tunnel should be $2 \mathrm{~m} \mathrm{~s}^{-1}$. Li et al. [26, 27] established the critical velocity model of cross channels based on critical Froude number, and the critical velocity formula in cross channels, including the height of the fire door and heat release rate, by scale model test. Hou et al. [28] considered the influence of train blockage on critical velocity in the cross channel. Jiang et al. [29] studied the factors influencing critical velocity in a railway tunnel cross channel based on $\pi$ theorem and similarity theory.

At present, researches on smoke control in doublehole tunnel mainly focus on network ventilation and critical velocity in the cross channel. However, network ventilation imposes high requirements on ventilation control systems, which contradicts the principle that simpler control is more effective in emergencies. Besides, fans in the cross channel make ventilation system more costly and complex.

Two adjacent tunnels and their cross channel are considered as a whole in this paper. By studying the influence of the ventilation system on smoke diffusion, flow velocity, and direction in the cross channels, we formulate a linkage control strategy of double-hole-tunnel ventilation system during fire accidents to control smoke in cross channels and main tunnels while ensuring people's safety.

\section{Design of Linkage Control Schemes for Ventilation System}

When a fire accident occurs in a highway tunnel, it is necessary to adjust the flow velocity in the tunnel to the critical velocity so as to avoid backflow smoke endangering the safety of people upstream of the fire. But, on the one hand, there are a lot of fans in the tunnel. If all fans are hard-booted, the instantaneous impulse current can reach 7 times of full-load current, and even if fans are softbooted, the impulse current will reach 3 times of full-load current. Therefore, the fans need to be booted group by group according to transformer capacity, and the starting interval of each fan group is $60 \sim 120 \mathrm{~s}$. On the other hand, according to fire accident analysis and fire test results at home and abroad, it generally takes 5 to 10 minutes for different tunnel fires to develop into disasters [30]. Therefore, it is extremely important to reasonably and orderly turn on fans for smoke control before a fire develops into a disaster.

Currently, the ventilation system of highway tunnels in China is mainly designed in accordance with the "Guidelines for Design of Ventilation of Highway Tunnel" (JTG/T D70/ 2-02-2014) [31] (hereinafter referred to as "Guidelines"). As required by "Guidelines," reasonable mechanical positive pressure air supply should be available in a special evacuation passage for smoke control. However, "Guidelines" fail to specify how to achieve such a mechanical positive pressure air supply.

Fans are usually equipped along with substations in highway tunnels over $3 \mathrm{~km}$ to save cable costs while they are usually installed at both ends of the tunnel in highway tunnels below $3 \mathrm{~km}$. Briefly, fans in the tunnel are divided into four groups (Figure 1), with the cross channel nearest to the fire as the boundary. Each group represents several fans installed at the inlet and outlet of the tunnel. Based on these four fan groups, six linkage control schemes are designed (Table 1).

The numerical simulation is established to compare and analyze the flow velocity, flow direction, and smoke flow in abovementioned six working conditions, and a linkage smoke control scheme for double-hole tunnel is eventually determined by verifying the reliability of numerical simulation results through scale model test. 


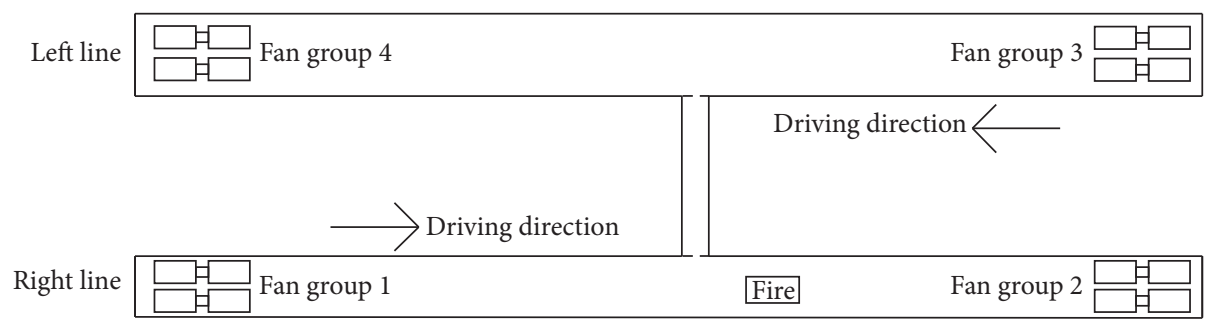

FiguRe 1: Layout of fan groups.

\section{Numerical Analysis of Linkage Control Scheme Performance}

3.1. Establishment of the Numerical Analysis Model. The tunnel model is built in Pyrosim software, and the fire dynamics simulator (FDS) is used to simulate the fire scene of highway double-hole tunnel. By comparing the numerical simulation results with the full-scale fire test results, NIST proved that FDS is accurate in predicting fire accidents [34].

In order to address the concerns both in two-lane and three-lane tunnels simultaneously, both the physical and the CFD models were built based on two-lane and three-lane tunnels. In this paper, the fire tunnel was two-lane tunnel, and the non-fire tunnel was three-lane tunnel.

When a fire accident occurs, the flow velocity upstream of the fire will be controlled by the ventilation system as the critical velocity. Cross channels away from the fire have little influence on the smoke control. Therefore, this paper mainly studies the influence of the cross channel closest to the fire upstream on smoke control. In order to reduce the influence of the entrance and exit on the airflow in the cross channel, the cross channel is located in the middle of the tunnel. The size of the cross channel is $6 \mathrm{~m} \times 5 \mathrm{~m}$, same as the cross channel for vehicle. The main tunnel is a common tunnel composed of two-lane and three-lane tunnel. The cross section of the main tunnel is shown in Figure 2.

The time it takes for a fire to develop into a disaster is affected by a lot of factors. In order to make the linkage control scheme adapt to various fire development scenarios, a steady fire source is selected, so that the maximum heat release rate (HRR) of the fire can be achieved as soon as possible. The maximum HRR selected is $30 \mathrm{MW}$, according to the "Guidelines" [31]. And the fire is set at the most disadvantageous position. When fire occurs in a double-hole tunnel, the cross channel in the upper stream of the fire will be open for people to evacuate. Therefore, the fire is set in the most disadvantageous fire location which is in the downstream of the fire and near the open cross channel. The fire is located at $10 \mathrm{~m}$ downstream of open cross channel in this paper.

The walls of the model are made from concrete with a thickness of $0.5 \mathrm{~m}$.

According to the state of fan groups, there are two conditions for the entrance and exit of the tunnel. One is that fans generate flow, thus causing an impact on the air in the tunnel, and the other is that all fans are off. The model boundary at the end with fans off is simplified as the open boundary. The model boundary at the end with fans on is simplified as the velocity boundary, which is determined by the pressure exerted by the omitted fans and the friction caused by the omitted length of the tunnel, to consider the complex influences. And the velocity at velocity boundaries is set at the critical velocity of longitudinal ventilation. According to the calculation formula of critical velocity proposed by $\mathrm{Wu}$ and Baker [13], the critical velocity of a two-lane tunnel is $3.0 \mathrm{~m} \mathrm{~s}^{-1}$ when the HRR is $30 \mathrm{MW}$.

$$
\begin{gathered}
\bar{H}=\frac{4 A}{P}, \\
Q^{*}=\frac{Q}{\rho_{0} C_{p} T_{0} \sqrt{g} \bar{H}^{5 / 2}}, \\
v^{*}=\frac{v_{c r}}{\sqrt{g \bar{H}}},
\end{gathered}
$$

If $\quad Q^{*}<0.20, v^{*}=0.40 \times 0.20^{-(1 / 3)} \times\left(Q^{*}\right)^{1 / 3}$,

$Q^{*} \geq 0.20, v^{*}=0.40$.

In formula (1)-(3), $A$ is the area of tunnel cross section, $P$ is the circumference of the tunnel, $\bar{H}$ is hydraulic diameter. $v^{*}$ is dimensionless critical velocity.

In the linkage control Schemes 5 and 6, fans in the nonfire tunnel are switched on in opposite directions, thus guiding the airflow into the cross channel and generating a strong wind to further affect people who are evacuating through the cross channel. As a result, it is necessary to limit the air volume in opposite directions in the non-fire tunnel. According to the cross-sectional area ratio of cross channel to tunnel and flow conservation law, the flow velocity of the velocity boundary on both sides of the non-fire tunnel is set to $0.5 \mathrm{~m} \cdot \mathrm{s}^{-1}$.

The grid size should be reasonably controlled for accurately simulating fire scenarios and saving time. One of the important factors is the characteristic diameter of the fire source $D^{*}$ (formula (1) [34]). When the HRR of fire is $30 \mathrm{MW}, D^{*}$ is $3.61 \mathrm{~m}$. And generally, $D^{*} / \delta x$ is greater than 4 ( $\delta x$ is the grid size); that is, $\delta x$ should be less than $0.90 \mathrm{~m}$. And the smaller grid size is, the more accurate the simulation result is.

$$
D^{*}=\left(\frac{Q}{\rho_{0} c_{p} T_{0} \sqrt{g}}\right)^{2 / 5} \text {. }
$$




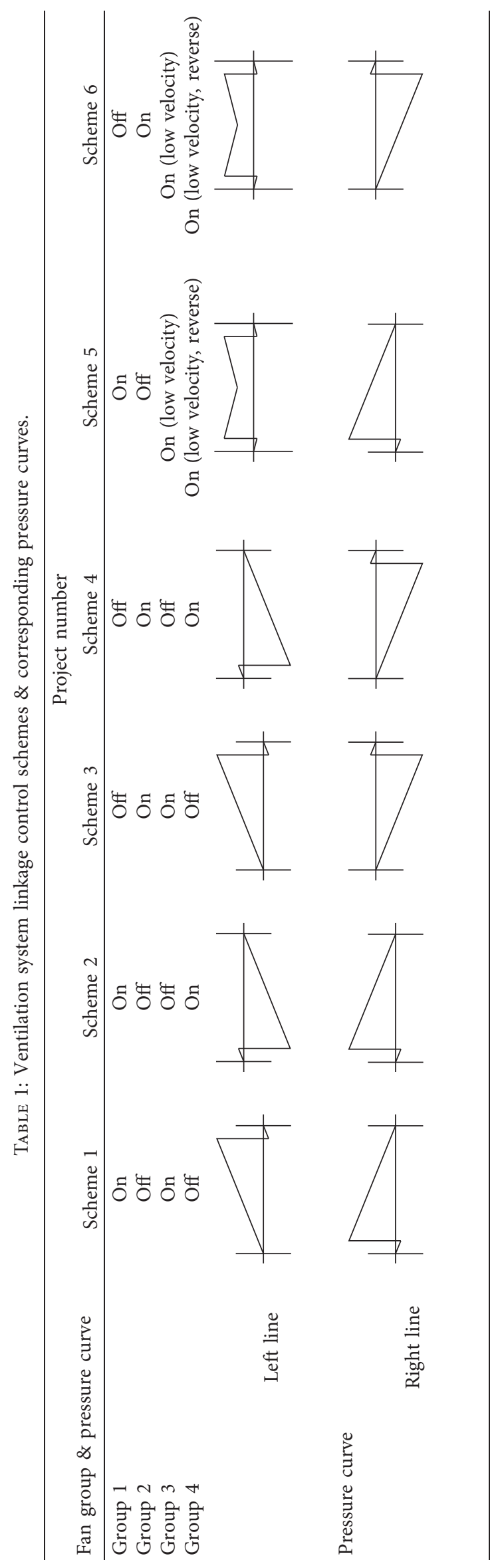




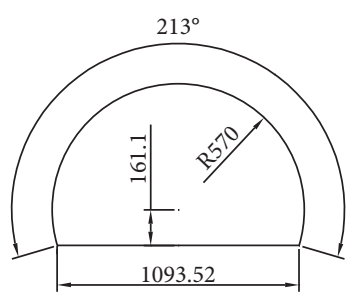

(a)

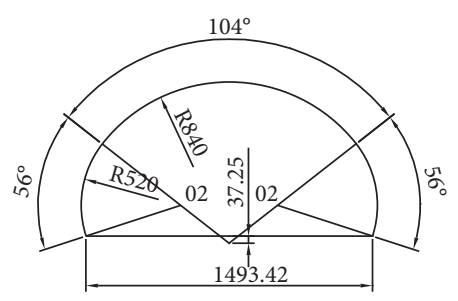

(b)

Figure 2: (a) Cross section of two-lane tunnel (unit: $\mathrm{cm}$ ). (b) Cross section of three-lane tunnel (unit: $\mathrm{cm}$ ).

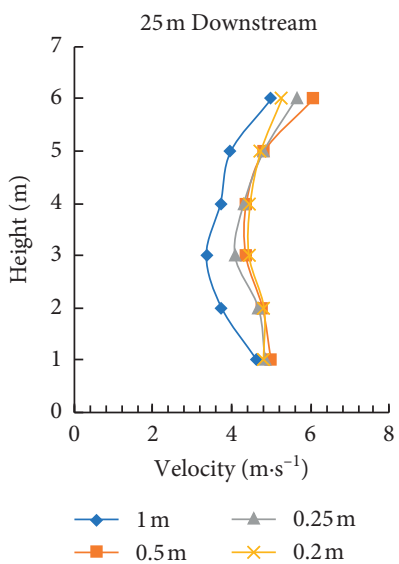

(a)

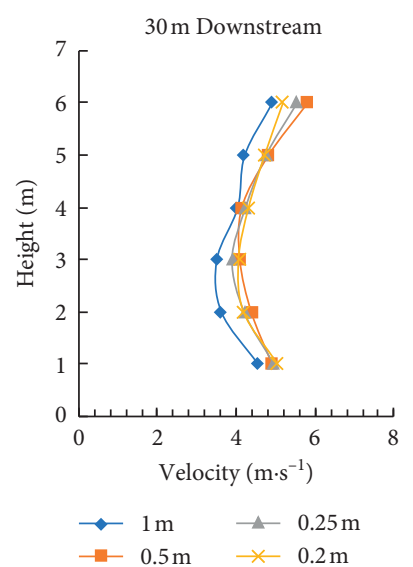

(b)

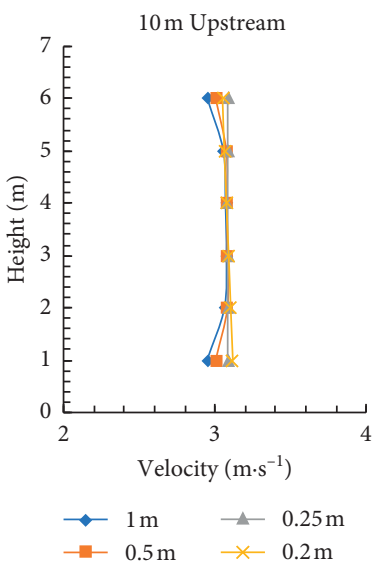

(c)

Figure 3: (a) Vertical distribution of the velocity at $25 \mathrm{~m}$ downstream of fire source with different grid sizes. (b) Vertical distribution of the velocity at $30 \mathrm{~m}$ downstream of fire source with different grid sizes. (c) Vertical distribution of the velocity at $10 \mathrm{~m}$ upstream of fire source with different grid sizes.

In formula (4), $Q$ is the HRR of the fire, $\rho_{0}$ is the air density, $c_{p}$ is the specific heat capacity of air, $T_{0}$ is the air temperature, and $g$ is the gravitational acceleration.

It is important to compare the simulation results for selecting a reasonable grid size. The cross section of test model is the same as that of a two-lane tunnel, with a length of $100 \mathrm{~m}$. The HRR of fire is $30 \mathrm{MW}$, and the longitudinal ventilation velocity at the boundary is $3.0 \mathrm{~m} \mathrm{~s}^{-1}$. The flow velocity and smoke distribution are mainly considered in this paper. Therefore, grid size can be determined by comparing the vertical distribution of the velocity in the tunnel suffering fire accidents. The vertical distribution of the velocity in the middle of the tunnel is shown in Figure 3. The vertical distribution of the velocity is similar when the grid is smaller than $0.5 \mathrm{~m}$. Therefore, in view of comparison results and the characteristics of the tunnel, the horizontal grid is set to $0.5 \mathrm{~m}$ and the vertical grid is set to $0.3 \mathrm{~m}$.

The middle part of the double-hole tunnel is extracted for simulation because a tunnel in real life is too long to be taken as a whole FDS model. In order to control the calculation time and accuracy, the length of the model needs to be controlled. Comparing the flow velocity in the cross channel of tunnels with different lengths for each scheme, it is found that as the length of the model increases, the velocity tends to become a certain velocity. For example, in Scheme 1 (Figure 4), when the

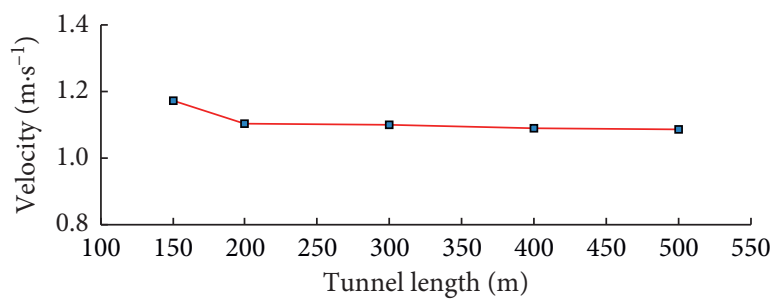

FIGURE 4: Flow velocity in the cross channel of tunnels with different lengths of Scheme 1.

length of the tunnel exceeds $200 \mathrm{~m}$, the flow velocity in the cross channel fluctuates around $1.1 \mathrm{~m} \cdot \mathrm{s}^{-1}$, and the flow velocity in the cross channel is not significantly affected by increasing the length of the tunnel. According to all comparison results, the length of the tunnel is set to $200 \mathrm{~m}$.

3.2. Numerical Simulation Results. The flow velocity, flow direction, and smoke flow in the cross channel corresponding to six linkage control schemes are summarized in Table 2. Among them, the simulation results of Schemes 2, 3, and 5 , which exhibit the greatest differences, are summarized here. 
TABLE 2: Summary of linkage control schemes for ventilation system.

\begin{tabular}{|c|c|c|c|c|c|c|c|c|c|}
\hline \multirow[t]{2}{*}{ Scheme } & \multicolumn{4}{|c|}{$\begin{array}{l}\text { Flow velocity of } \\
\text { fan group } \\
\left(\mathrm{m} \cdot \mathrm{s}^{-1}\right)\end{array}$} & \multicolumn{3}{|c|}{ Smoke diffusion } & \multicolumn{2}{|c|}{ Flow velocity and direction in cross channel } \\
\hline & $1 \#$ & 2\# & $3 \#$ & $4 \#$ & $\begin{array}{l}\text { Time to cross } \\
\text { channel (s) }\end{array}$ & $\begin{array}{c}\text { Time to non-fire } \\
\text { tunnel (s) }\end{array}$ & $\begin{array}{c}\text { Amount of smoke } \\
\text { intrusion }\end{array}$ & $\begin{array}{c}\text { Flow velocity } \\
\left(\mathrm{m} \cdot \mathrm{s}^{-1}\right)\end{array}$ & Flow direction \\
\hline 1 & 3.0 & 0.0 & 3.0 & 0.0 & 32 & 62 & Little & $\begin{array}{l}1.1 \text { (Top) }<1.0 \\
\text { (Others) }\end{array}$ & $\begin{array}{c}\text { Top: fire tunnel to non-fire } \\
\text { Tunnel } \\
\text { Others: disordered }\end{array}$ \\
\hline 2 & 3.0 & 0.0 & 0.0 & 3.0 & 8 & 15 & Large & $\begin{array}{c}3.0 \text { (Top) }<1.0 \\
\quad \text { (Others) }\end{array}$ & $\begin{array}{c}\text { Top and bottom: fire tunnel to } \\
\text { non-fire Tunnel } \\
\text { Others: disordered }\end{array}$ \\
\hline 3 & 0.0 & 3.0 & 3.0 & 0.0 & 75 & - & None & 3.2 & $\begin{array}{l}\text { non-fire tunnel to fire tunnel } \\
\text { Minority: non-fire tunnel to }\end{array}$ \\
\hline 4 & 0.0 & 3.0 & 0.0 & 3.0 & 45 & - & None & $<1.0$ & $\begin{array}{l}\text { fire Tunnel } \\
\text { Majority: disordered }\end{array}$ \\
\hline 5 & 3.0 & 0.0 & 0.5 & 0.5 & - & - & None & 4.1 & Non-fire tunnel to fire tunnel \\
\hline 6 & 0.0 & 3.0 & 0.5 & 0.5 & 225 & - & None & 4.5 & Non-fire tunnel to fire tunnel \\
\hline
\end{tabular}

3.2.1. Scheme 2. The airflow from the fire tunnel to the nonfire tunnel at the top and bottom of the cross channel can be obviously seen. The flow velocity of the airflow along the cross channel is continuously decreasing, and the flow velocity fluctuates greatly, with an average velocity of $3 \mathrm{~m} \mathrm{~s}^{-1}$. Most of the cross channels are mostly disordered and exhibit low-speed airflow with a flow velocity of less than $1 \mathrm{~m} \mathrm{~s}^{-1}$. Influenced by the stable airflow from the fire tunnel to the non-fire tunnel, the backflow of smoke to the cross channel is accelerated. The backflow smoke penetrates into the cross channel from the top eight seconds after the fire begins and starts to rapidly and massively penetrate into the non-fire tunnel from the top 15 seconds after the fire begins. Affected by the turbulent airflow in the middle of the cross channel, smoke in the cross channel rapidly diffuses and occupies the entire space of the cross channel, thus making it more difficult for people to escape. As a large amount of heat smoke is sucked into the cross channel, the temperature rises sharply, with a maximum temperature of $75^{\circ} \mathrm{C}$ at a height of $1.8 \mathrm{~m}$, thus causing great harm to people who are evacuating in the upper stream of the fire. Therefore, such type of linkage control scheme should not be adopted.

3.2.2. Scheme 3. There is a stable airflow from the non-fire tunnel to the fire tunnel in the cross channel with an average velocity of $3.2 \mathrm{~m} \mathrm{~s}^{-1}$. The flow distribution is relatively uniform. And the flow velocity is stable at the upper half part of the cross channel, thus effectively preventing the smoke from flowing into the cross channel and providing sufficient fresh air to guarantee the safety of the evacuees. However, no fan group is running at the entrance of the fire tunnel, so a small amount of smoke flows backward at the top of the tunnel.

3.2.3. Scheme 5. The multidirectional airflow is poured into the cross channel in the initial stage. As a result, the flow velocity increases rapidly to $4 \mathrm{~m} \cdot \mathrm{s}^{-1}$ and fluctuates continuously between $2 \mathrm{~m} \cdot \mathrm{s}^{-1}$ and $5 \mathrm{~m} \cdot \mathrm{s}^{-1}$. The airflow significantly changes, exhibiting a disordered state. After $100 \mathrm{~s}$, the airflow in the cross channel gradually tends to stabilize, and the airflow from the non-fire tunnel to the fire tunnel is stable, with an average velocity of $4.1 \mathrm{~m} \cdot \mathrm{s}^{-1}$. When the airflow in the cross channel is stable, the airflow direction is consistent with insignificant changes in the horizontal and vertical direction. The airflow from the non-fire tunnel is guided to the fire tunnel by the structure of the tunnel, and sufficient fresh airflow is available for protecting the cross channel from being affected by hot gas. The airflow from the non-fire tunnel is beneficial for controlling smoke to flow towards the downstream of the fire, thus ensuring the safety of the personnel who are escaping in the upstream of the fire.

The distribution of flow velocity in the cross channel, the distribution of flow velocity as time changes, and smoke diffusion at $300 \mathrm{~s}$ are shown in Figures (5)-(7).

The linkage control scheme mainly aims to create stable and favorable evacuation conditions for personnel in the upper stream of the fire. Schemes 1 and 2 cannot prevent smoke from intruding into the cross channel; Scheme 4 has low and insufficiently stable flow velocity; Scheme 6 is similar to Scheme 5, but it is much less effective in controlling smoke than Scheme 5. Therefore, according to the numerical simulation results, the proposed schemes are as follows:

(1) Scheme 3 (OFF-ON-ON-OFF) is simple and convenient. According to the pressure curve, the suction effect of Fan Group 2 results in negative pressure in the fire tunnel, and the pressure on the side of the cross channel facing the non-fire tunnel is higher than that on the other side facing the fire tunnel. Therefore, the relatively stable airflow can be generated in the cross channel from the non-fire tunnel to the fire tunnel, thus effectively preventing smoke from penetrating into the cross channel. However, a small amount of smoke flows backward at the top of the tunnel. Scheme 3 is not effective in preventing smoke from flowing backward.

(2) Scheme 5 (ON-OFF-ON (Low Velocity)-ON (Low Velocity, Reverse)) has a significant effect on smoke control in the fire tunnel and the cross channel. No backflow smoke occurs in the fire tunnel, the total 


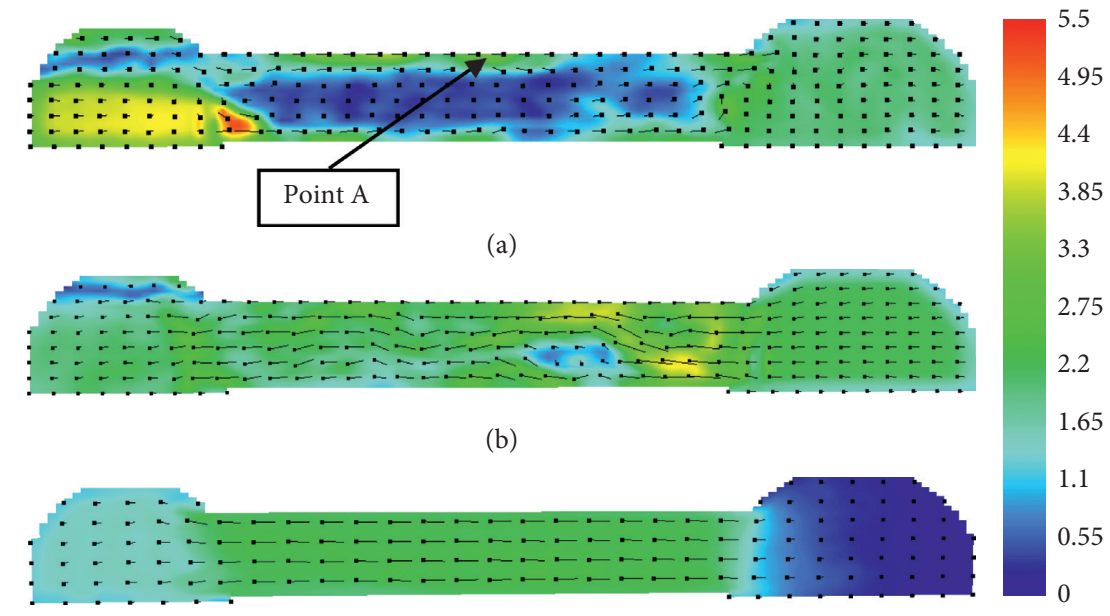

(c)

Figure 5: (a) Vector-graph of flow velocity $\left(\mathrm{ms}^{-1}\right)$ in the cross channel of Scheme 2. (b) Vector-graph of flow velocity $\left(\mathrm{ms}^{-1}\right)$ in the cross channel of Scheme 3. (c) Vector-graph of flow velocity $\left(\mathrm{ms}^{-1}\right)$ in the cross channel of Scheme 5.

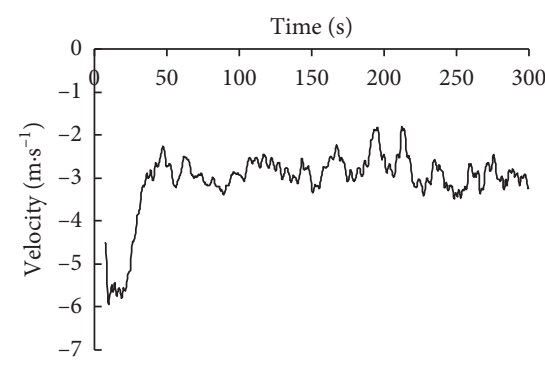

(a)

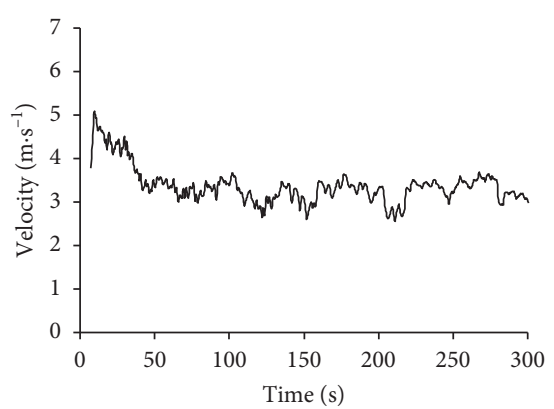

(b)

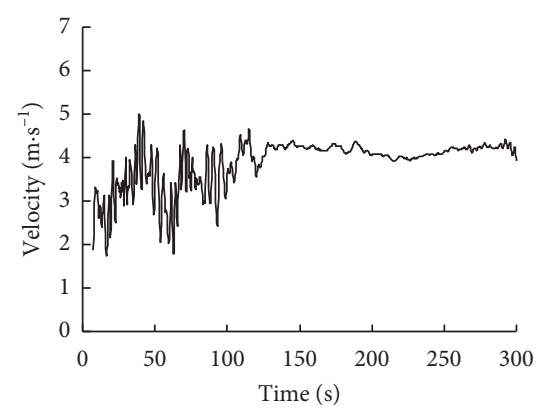

(c)

FIgURe 6: (a) Flow velocity $\left(\mathrm{ms}^{-1}\right)$ with time at point a of Scheme 2. (b) Flow velocity $\left(\mathrm{ms}^{-1}\right)$ with time at point a of Scheme 3. (c) Flow velocity $\left(\mathrm{ms}^{-1}\right)$ with time at point a of Scheme 5 .

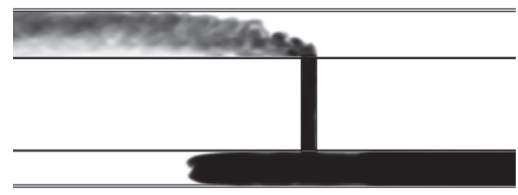

(a)

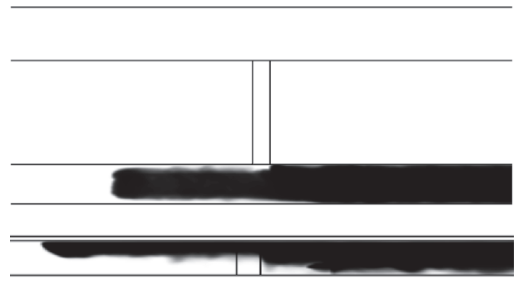

(b)

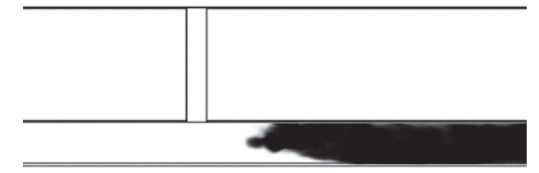

(c)

Figure 7: (a) Smoke diffusion at $300 \mathrm{~s}$ of scheme 2. (b) smoke diffusion at $300 \mathrm{~s}$ of scheme 3. (c) smoke diffusion at $300 \mathrm{~s}$ of scheme 5.

power of the required fan is smaller, and the airflow velocity in the cross channel is stable and evenly distributed.

\section{Physical Model Test of Linkage Control for Ventilation System}

In order to verify the reliability of numerical simulation results and smoke control effect of Scheme 3 and Scheme 5, further research was carried out by physical model test.
Highway tunnel is curved in shape, and the temperature of the high-power fire is extremely high. Therefore, the physical model of the tunnel is made of iron sheet, and a flexible asbestos board is laid on the model near the fire to reduce heat dissipation.

The similarity method between prototype and model is the Froude simulation method, which means prototype and model have the same Froude number. The Reynolds number has to be selected from the turbulent region so that the flow of the model is similar to that of the 


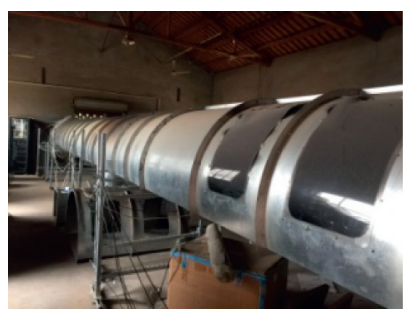

(a)

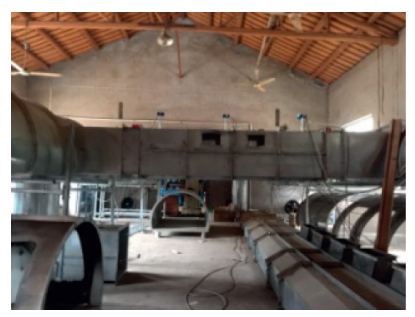

(b)

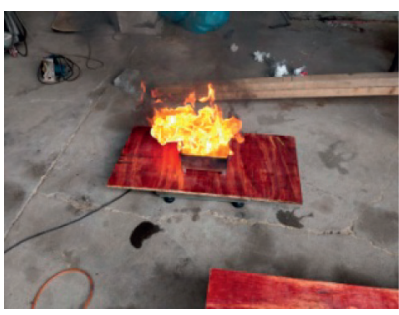

(c)

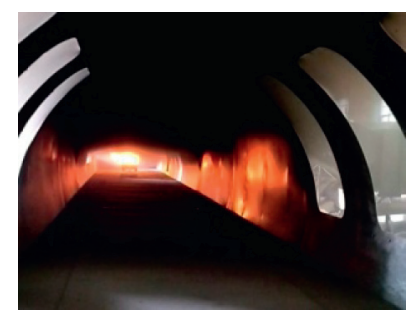

(d)

Figure 8: (a) Model of tunnel. (b) Model of cross channel. (c) Testing the heat release rate of fire source. (d) Testing the smoke diffusion when a fire occurs in a two-lane tunnel.

prototype. And the Reynolds number generally is greater than $10^{5}$. As the power of the fire is $30 \mathrm{MW}$ in prototype, the length ratio of the prototype and model is set to $1: 10$ to adapt to cost-effective test conditions and limited test sites and achieve accurate results. Open areas are built on the tunnel and cross tunnel and covered by transparent windows made from polymethyl methacrylate (PMMA) for observing smoke flow. The model test is shown in Figure 8 .

In order to better control the power of the fire and accurately simulate the fire in the tunnel, a square oil sump with gasoline and diesel as fuel is used for fire simulation. The change in the mass of the fuel during combustion is monitored by a mass sensor in a real-time manner. The HRR of the fuel is calculated according to the HRR formula (5). The size of the fuel pan is $42 \mathrm{~cm} \times 42 \mathrm{~cm}$ and the ratio of gasoline to diesel is $1: 5$ to obtain $95 \mathrm{~kW}$ (corresponding to $30 \mathrm{MW}$ fire in prototype).

$$
Q=\varphi \times \dot{m} \times H_{c} .
$$

In formula (5), $\varphi$ is the combustion efficiency factor, 0.7, [32]; $\dot{m}$ is the mass loss rate of fuel; and $H_{c}$ is the calorific value of fuel. The calorific value of gasoline and diesel is $43,110 \mathrm{~kJ} / \mathrm{kg}$ and $46,040 \mathrm{~kJ} / \mathrm{kg}$, respectively.

The flow velocity is stimulated by fans at the entrance of the tunnel in the model test, thus corresponding to the velocity boundary in the FDS model. The wind speed sensor and frequency converter are used to adjust the flow velocity in the tunnel for each working condition, and the flow velocity is set according to the velocity ratio of $(1: 10)^{0.5}$. As the model is not long and it takes a long distance for the flow to develop into full turbulence when air is transported from the fan into the tunnel, a sheet of grille is set up at $1 \mathrm{~m}$ downstream of the fan to achieve full turbulence as soon as possible [33].

4.1. Sensors and Data Acquisition. The test data includes the flow velocity in the cross channel and tunnel, flow direction, and smoke diffusion conditions. The sensors are installed as follows:

Flow velocity in the tunnel: Wind speed sensors are installed at the center of the cross section, which is at $5 \mathrm{~m}$ downstream of each fan.
Flow velocity in the cross channel: The numerical simulation results show that the flow velocity at the top of the cross channel is relatively stable, so the data about the flow velocity is suggested to be acquired at this position. Therefore, the three sensor points are located at the top of the cross section so that the cross channel can be divided into four equal sections (Figure 9). Two wind sensors are installed at each sensor point for testing the airflow in opposite directions.

Smoke diffusion: The condition of smoke diffusion is manually observed and recorded through transparent windows. Wet, white, fine cloth is placed in the cross channel to facilitate smoke observation.

The ratio of prototype time to model time is $1:(1 / 10)^{1 / 2}$. It takes $96 \mathrm{~s}$ for the fire to develop in the model while it will take $300 \mathrm{~s}$ in the prototype. Therefore, the test results need to be rapidly and efficiently acquired. The PLC data acquisition system (Figure 10) is used to automatically collect, unify, and output all sensor data in this study. The data acquisition period is set to $1 \mathrm{~s}$, which meets the needs of the model test.

\subsection{Model Test Results}

4.2.1. Flow Velocity and Direction in the Cross Channel. The flow velocity test results at three measuring points in the cross channel under different ventilation system linkage control schemes within $96 \mathrm{~s}$ (corresponding to $300 \mathrm{~s}$ in the prototype) after ignition of the fire are extracted and compared with the numerical simulation results converted according to the similarity ratio of flow velocity to verify whether the numerical simulation results are consistent with the actual situation. The model test results at three measuring points are relatively close to the numerical simulation results. Therefore, the flow velocity of Point 2 is selected for comparison, and the comparison of the proposed schemes is shown in Figure 11.

By comparing the numerical simulation results and model test results of two ventilation system linkage control schemes, it is found that the results are similar.

(i) Trends: In Scheme 3, the flow velocity in the cross channel in both the model test and numerical simulation increased before gradually becoming stable. In Scheme 5, the flow velocity in the cross channel 


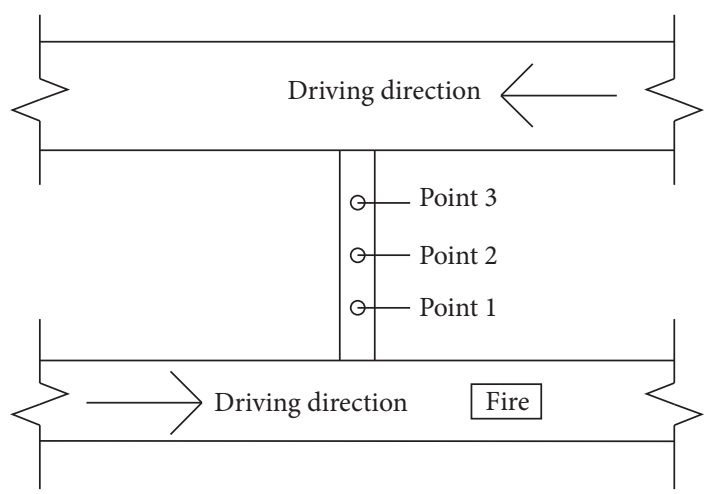

FIGURE 9: Arrangement of measuring points.

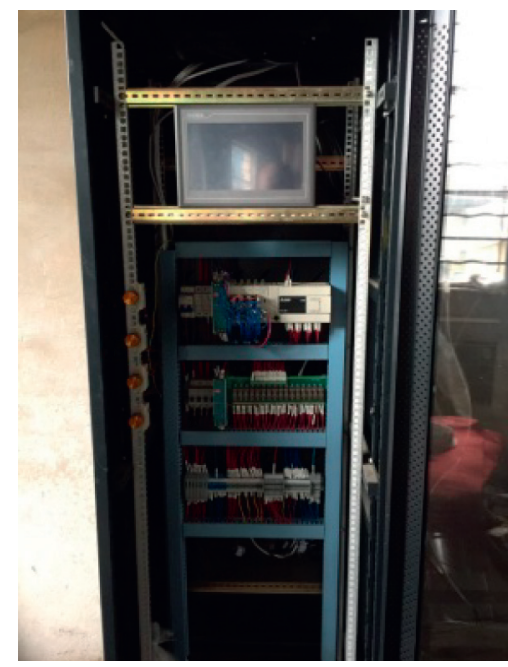

Figure 10: PLC data acquisition system.

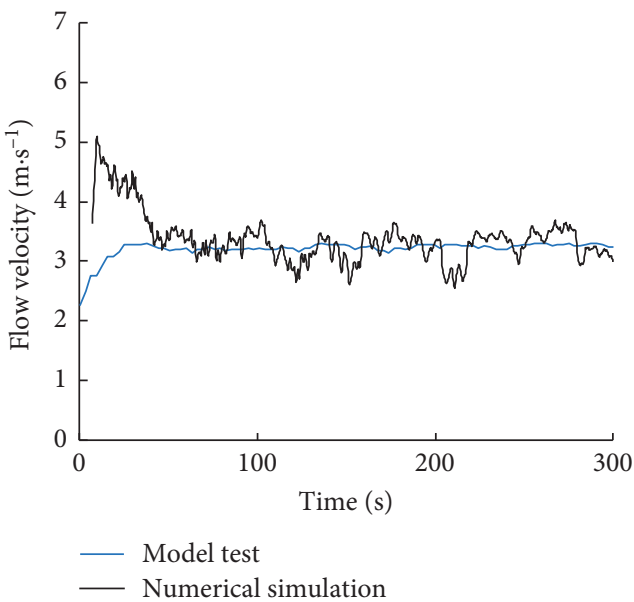

(a)

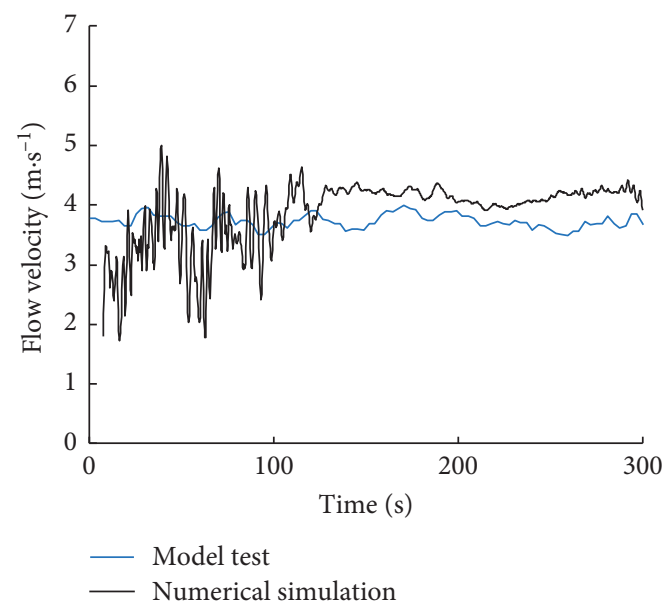

(b)

Figure 11: (a)Flow velocity at Point 2 of Scheme 3. (b)Flow velocity at Point 2 of Scheme 5.

rapidly increased to about $4 \mathrm{~m} \mathrm{~s}^{-1}$, and then gradually stabilized. However, due to the different types of fire, the flow velocity changes greatly in the initial stage of the numerical simulation, during which the flow velocity value is somewhat different from that in the model test, but the difference is not significant. It takes 
a short time for the flow velocity to rapidly change, thus having an insignificant effect on linkage control. Therefore, such a difference can be neglected.

(ii) Flow velocity: The average flow velocity of Scheme 3 is $3.2 \mathrm{~m} \mathrm{~s}^{-1}$ for the numerical simulation, and it is $3.2 \mathrm{~m} \mathrm{~s}^{-1}$ for the model test. The average flow velocity of Scheme 5 is $4.1 \mathrm{~m} \mathrm{~s}^{-1}$ for the numerical simulation, and the average flow velocity of Scheme 5 is $3.8 \mathrm{~m} \mathrm{~s}^{-1}$ for the model test. The values of flow velocity for the model test agree well with those in the numerical simulation.

(iii) Flow direction: In the numerical simulations and model tests of Schemes 3 and 5, the flow direction is always from the non-fire tunnel to the fire tunnel.

4.2.2. Smoke Diffusion. In Scheme 3, since Fan Group 2 is switched on in the fire tunnel to pump the smoke out of the tunnel, the pressure of the fans directly acts on the airflow downstream of the fire. As a result, the airflow obviously changes, and the smoke distributes in a disorderly manner and diffuses downstream of the fire.

In Scheme 5, due to the high velocity of the airflow in the cross channel, a strong airflow is generated in the fire tunnel, thus disturbing the smoke near the fire but having little influence on the smoke far away from the fire. The smoke in this area is still hierarchically distributed, and it is also uniformly distributed and highly visible between the layer of the smoke and the bottom of the tunnel.

The time it takes for backflow smoke to penetrate into the cross channel, the time it takes for backflow smoke to reach the non-fire tunnel and the amount of the smoke that reaches the non-fire tunnel are compared by examining the results of the model test and numerical simulation. In order to facilitate observation and statistics, the amount of the smoke that reaches the non-fire tunnel is calculated mainly based on smoke particles. For the convenience of comparison, the time obtained in the model test is converted into real time according to the time similarity ratio, and the results are summarized in Table 3. According to the table, the trends of the smoke flow are the same for the same scheme in both the numerical simulation and model test. The fire in the numerical simulation is steady, so the smoke diffuses faster in the initial stage, thus resulting in the difference of about $26 \mathrm{~s}$. The smoke flow in the numerical simulation is similar to that in the model test.

4.2.3. Result Comparison. In summary, according to the comparison results of flow velocity, flow direction, and smoke flow in the cross channel, the results of numerical simulation and model test are similar. In other words, the results of numerical simulation are similar to that of the actual situation. The parameters of the numerical simulation can be used to study the influence of ventilation system linkage control on smoke, and the numerical simulation results can be used to determine the ventilation system linkage control scheme.
According to the smoke flow in the model test, Scheme 3 can easily disrupt the smoke downstream of the fire, thus making it diffuse and affect the evacuees downstream of the fire, while Scheme 5 only disturbed the smoke in the area near the fire. Therefore, Scheme 5 is safer and more suitable for fire rescue in double-hole tunnels.

\section{Applicability of Linkage Control Scheme}

In order to further determine the recommended Scheme 5 for linkage control, the following influencing factors need to be analyzed:

(1) It is assumed in the above research that the fire accident occurs in the middle of the tunnel. But it is impossible to determine whether the linkage control scheme is still effective for the fire accident near the entrance or exit.

(2) Fan Group 4 needs to be switched on in Scheme 5, and then air is supplied to prevent smoke from penetrating into the cross channel by working together with Fan Groups 1, 3, and 4, which will take a period of time. Therefore, it needs to be determined whether Scheme 5 can timely control smoke in the cross channel upstream of the fire.

(3) If a fire accident occurs in an extra-long tunnel, doors of some cross channels will be opened. But it is necessary to determine the influence of the quantity of the door on the smoke control effect of Scheme 5.

5.1. Analysis of Influence of Fire Location. The air pressure is associated with the location in the same ventilation conditions in the tunnel; thus, the situation of air pressure at both sides of given cross channel is different when the fire occurs at the entrance/exit or in the middle of the tunnel. Therefore, the fire location should be taken into consideration for Scheme 5 .

By increasing the difference in the length between front and back sections of the cross channel to simulate a fire located near the entrance or exit of the tunnel, we can study whether Scheme 5 is still suitable for smoke prevention in the cross channel. According to the foregoing numerical simulation, the key parameters are selected and the model is established. The length of the front and back sections of the cross channel is adjusted to $500 \mathrm{~m}$ and $100 \mathrm{~m}$, respectively. And then smoke distribution and flow velocity in the cross channel are analyzed when the fire occurs in different locations (arrangement of measuring points is the same as Figure 9).

When the fire occurs in different locations in the tunnel, the smoke distribution at $300 \mathrm{~s}$ is shown in Figure 12. When the fire occurs near the entrance or exit of the tunnel, Scheme 5 can still generate stable airflow in the cross channel from non-fire tunnel to fire tunnel, and prevent the smoke from flowing back.

When fire occurs in different locations in the tunnel, the flow velocity in the cross channel is as shown in Table 4 . The flow velocity in the cross channel is all around $4 \mathrm{~m} \mathrm{~s}^{-1}$ when 
TABLE 3: Comparison of time it takes for the smoke to spread to the cross channel and the amount of smoke intrusion of Scheme 3 and Scheme 5 .

\begin{tabular}{|c|c|c|c|}
\hline Results & & Scheme 3 & Scheme 5 \\
\hline \multirow{3}{*}{ Passing time of cross channel (s) } & Numerical simulation & 75 & - \\
\hline & Model test (after conversion) & 101 & - \\
\hline & Time difference & 26 & - \\
\hline \multirow{2}{*}{ Amount of smoke intrusion } & Numerical simulation & None & None \\
\hline & Model test (after conversion) & None & None \\
\hline
\end{tabular}

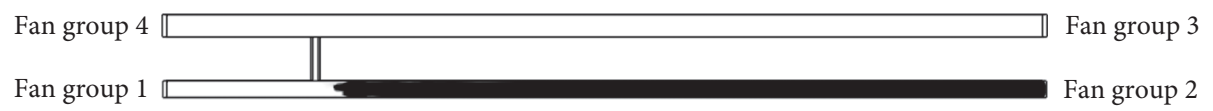

(a)

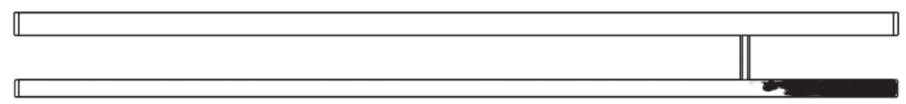

(b)

Figure 12: (a) Smoke diffusion at $300 \mathrm{~s}$ when the fire is near the entrance of the fire tunnel. (b) Smoke diffusion at $300 \mathrm{~s}$ when the fire is near the exit of the fire tunnel.

the fire occurs in different locations. The difference in the flow velocity is caused by the pressure change along the way in the fire tunnel.

Although fire location has an impact on the flow velocity in the cross channel under Scheme 5, smoke is effectively controlled and the smoke downstream of the fire can be stabilized under these three working conditions. Therefore, smoke in the cross channel and fire tunnel can be stably controlled by the ventilation system linkage control scheme to ensure the safety of personnel upstream of the fire when fire occurs in different locations.

5.2. Time Effect Analysis of Stable Airflow. Scheme 5 (ONOFF-ON (Low Velocity) - ON (Low Velocity, Reverse)) requires adjusting the direction of fans in the non-fire tunnel to form a stable low-speed opposite flow. Thus, fan needs to be rotated and opened to stabilize the flow velocity, which takes long time. Therefore, it is necessary to verify the time to stabilize airflow in the cross channel of Scheme 5.

The process of Scheme 5 involves preventing nonrescue vehicles from entering the non-fire tunnel, reversing and turning on Fan Group 4, turning on Fan Group 3, and stabilizing the flow velocity. Among them, it takes about $60 \mathrm{~s}$ to switch on fan. The "Guidelines" [31] require reversing fans within $90 \mathrm{~s}$. The duration of stable flow velocity needs to be determined by calculation. Therefore, the following assumptions are made for the numerical simulation:

$0 \mathrm{~s}$ : Flow in the tunnel is mainly caused by moving vehicles, and it is called as piston wind, which is set to $6 \mathrm{~ms}^{-1}$ in this paper.

$0 \mathrm{~s} \sim 60 \mathrm{~s}$ : The piston wind velocity decreases as the number and velocity of moving vehicles decreases; Fan
Group 3 starts up and Fan Group 4 starts to turn around. The velocity boundary corresponding to Fan Group 3 is set to changing from $6 \mathrm{~m} \mathrm{~s}^{-1}$ to $0.5 \mathrm{~m} \mathrm{~s}^{-1}$ and the boundary corresponding to Fan Group 4 is set to open boundary.

60 s: Fan Group 3 has been turned on, and from now on, it is assumed that no non-rescue vehicle is running in the tunnel.

60 s 90 s: Fan Group 3 is on and Fan Group 4 is turning around.

90 s: Fan Group 4 stops turning around.

90 s 150 s: Fan Group 4 is turned on. The velocity boundary corresponding to Fan Group 4 is set to changing from $0 \mathrm{~m} \cdot \mathrm{s}^{-1}$ to $0.5 \mathrm{~m} \mathrm{~s}^{-1}$.

The length of the tunnel in the simulation model is $1,500 \mathrm{~m}$, and the cross channel is located in the middle of the tunnel. The variation of flow velocity in the cross channel during Scheme 5 is measured (Figure 13). In $0 \mathrm{~s} \sim 60 \mathrm{~s}$, influenced by the decreasing flow velocity in the tunnel, the flow velocity in the cross channel decreases continuously, and reverse flow appears in the cross channel from the fire tunnel to the non-fire tunnel. At $60 \mathrm{~s} \sim 90 \mathrm{~s}$, the flow velocity in the cross channel stops decreasing because of the stable airflow in the tunnel. In $90 \mathrm{~s} \sim 150 \mathrm{~s}$, Fan Group 4 stops turning around and begins to work, and the airflow in the cross channel flows to the fire tunnel. After Fan Group 4 is turned on, the flow velocity in the cross channel tends to be continuously stable. After Fan Group 4 is turned on for $30 \mathrm{~s}$, that is, after the scheme lasts for $180 \mathrm{~s}$, the flow velocity in the cross channel is obviously stable.

In Scheme 5, it takes about $30 \mathrm{~s}$ for the airflow to become stable after fan is in place, and it takes about $180 \mathrm{~s}$ to complete the entire process. The start-up time of Scheme 5 is mainly affected by the mechanical control efficiency of the 
TABLE 4: Comparison of flow velocity $\left(\mathrm{ms}^{-1}\right)$ in the cross channel when the fire occurs in different locations.

\begin{tabular}{lccc}
\hline Measuring & & Points fire location & \\
& Point 1 & Point 2 & Point 3 \\
\hline Entrance section & 5.16 & 5.14 & 5.06 \\
Middle section & 4.14 & 4.16 & 4.10 \\
Exit section & 3.40 & 3.44 & 3.27 \\
\hline
\end{tabular}

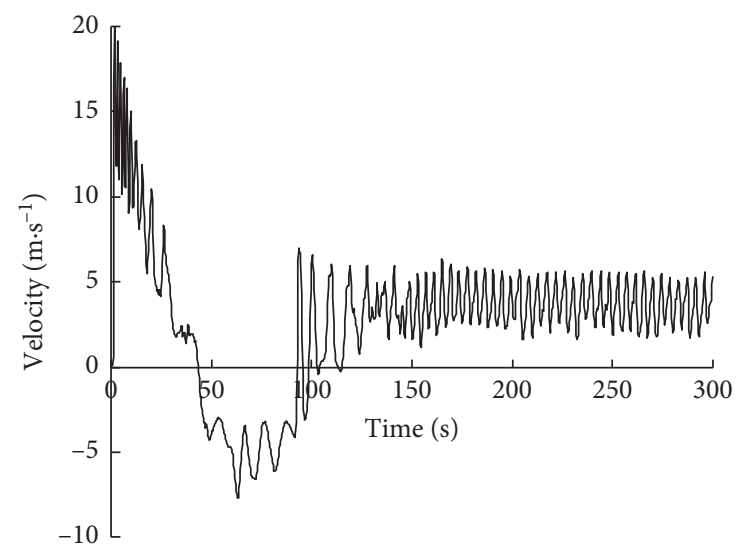

FIGURE 13: Variation of flow velocity in the middle of cross channel when the stable low-speed opposite flow appears in the non-fire tunnel.

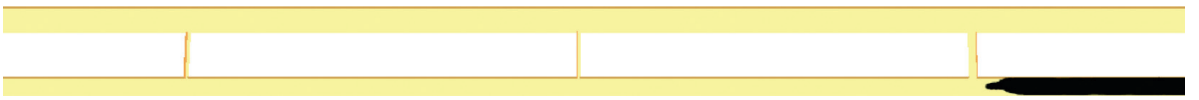

Figure 14: Smoke diffusion at $300 \mathrm{~s}$ with three open cross channels.

ventilation system. The faster the fans reverse and reach the flow velocity, the less the start-up time.

In the actual implementation process of Scheme 5, the reverse fans are low-speed and divided into two groups. The start-up time of Scheme 5 is limited. Therefore, compared with the mechanical pressure smoke prevention methods commonly adopted in some tunnel cross channels, the start-up time will not have a negative impact on timely rescue, and Scheme 5 can be used for smoke control in the cross channel and tunnels.

In addition, it is suggested that in Scheme 5, it is necessary to open the door on the side of the cross channel facing the non-fire tunnel after the reverse fans are turned on to prevent the smoke in the fire tunnel from flowing backward and penetrating into the non-fire tunnel due to the suction effect caused by the continuous decrease of the flow velocity in the non-fire tunnel.

5.3. Impact Analysis of Multiple Cross Channels. When a fire accident occurs in an extra-long tunnel, several cross channels will be opened for evacuees and rescue vehicles. However, if more than one cross channels are opened, the airflow in the tunnel will be affected. Therefore, a model with three open cross channels is established to study the influence of multiple open cross channels on the smoke distribution and the airflow in the most dangerous cross channel. The spacing of cross channels is $250 \mathrm{~m}$ and the other key parameters are the same as Scheme 5 in Section 3.
TABLE 5: Comparison of flow velocity $\left(\mathrm{ms}^{-1}\right)$ in the most dangerous cross channel.

\begin{tabular}{lccc}
\hline \multirow{2}{*}{ Type } & \multicolumn{3}{c}{ Measuring points } \\
& Point 1 & Point 2 & Point 3 \\
\hline Multiple cross channels & 3.82 & 3.85 & 3.87 \\
Single cross channel & 4.14 & 4.16 & 4.10 \\
\hline
\end{tabular}

According to the smoke distribution at $300 \mathrm{~s}$ shown in Figure 14, Scheme 5 can still effectively control the smoke in the downstream of the fire in the tunnel with three open cross channels. According to Table 5, when the three cross channels are opened, the flow velocity in the most dangerous cross channel decreases $0.3 \mathrm{~m} \mathrm{~s}^{-1}$. However, Scheme 5 can still effectively prevent smoke from moving into the cross channels.

Therefore, based on the comparison results of smoke distribution and flow velocity in the cross channels, when several cross channels are opened, Scheme 5 can still generate stable airflow in the cross channels and effectively prevent the smoke from flowing backward.

\section{Conclusion}

In order to prevent the smoke from flowing back and penetrating into the adjacent tunnel through the cross channels, this paper compares and analyzes the smoke control effects of different ventilation system linkage control 
schemes from the smoke diffusion, flow velocity, and direction in the cross channel through numerical simulations and model tests. The following conclusions are made:

(1) The recommended linkage control scheme: The fans upstream of the fire in the fire tunnel are turned on, and the fans on both sides of the cross channel opposite to each other in the adjacent non-fire tunnels are turned on to generate positive pressure. The velocity of opposite airflow in non-fire tunnel is suggested to be $0.5 \mathrm{~ms}^{-1}$ and that in the fire tunnel should be controlled to the critical velocity. This scheme does not require too many fans while still being effective in controlling smoke in the two holes and cross channels and preventing the smoke from flowing back and penetrating into the adjacent tunnel through cross channels, thus ensuring evacuee's safety. The scheme applies to fire accidents in a variety of locations and evacuation can be expedited by appropriately increasing the number of open cross channels.

(2) It is required to take $180 \mathrm{~s}$ to form low-speed opposite airflow in the non-fire tunnel, mainly composed of the time for fans to reverse and start, and the time to stabilize airflow is minor.

(3) The changes in the airflow in the non-fire tunnel need to be considered before cross channels are opened because the pressure change caused by decrease in the flow velocity in the non-fire tunnel needs to be avoided so that the smoke in the fire tunnel will not be sucked.

(4) The airflow distribution in cross channels and the influence of fans on smoke backflow and layer distribution in the tunnel need to be taken into account for determining the ventilation system linkage control scheme.

It is complex but important to formulate a strategy for controlling smoke in the tunnel and cross channels during fire accidents, and there are a lot of influencing factors, including the difference in the air pressure between inside and outside the tunnel, vehicles inside the tunnel, etc., which are not considered herein. Moreover, the conditions of both the model test and the numerical simulation are simpler than that in the real life, thus resulting in various errors. In the future, a full-scale fire test similar to the actual situation is advised to be conducted to further study the feasibility of the linkage control scheme of ventilation system.

\section{Data Availability}

The data used to support the findings of this study are available from the corresponding author upon request.

\section{Conflicts of Interest}

The authors declare no conflicts of interest.

\section{Acknowledgments}

This research was funded by the National Natural Science Foundation of China, grant number 51678530.

\section{References}

[1] Editorial Department of China Journal of Highway and Transport, "Review on China's tunnel engineering research: 2015," China Journal of Highway and Transport, vol. 28, no. 5, pp. 1-65, 2015.

[2] G. A. Khoury, "EU tunnel fire safety action," Tunnels and Tunnelling International, vol. 35, no. 4, pp. 20-23, 2003.

[3] A. Haack, "Fire protection in traffic tunnels: general aspects and results of the EUREKA project," Tunnelling and Underground Space Technology, vol. 13, no. 4, pp. 377-381, 1998.

[4] H. Zhu, F. Peng, and Z. Yan, "Present situation and enlightenment of fire safety research on traffic tunnels at home and abroad," Civil Defence Realm, no. S1, pp. 135-139, 2006.

[5] H. Ingason and A. Lönnermark, "Large-scale fire tests in the runehamar tunnel-heat release rate (HRR)," in Proceedings of International Symposium on Catastrophic Tunnel Fires (CTF), SP Report, Borås, Sweden, pp. 20-21, November 2003.

[6] W. Peng, R. Huo, L. Hu, H. Wang, and R. Yang, "Full scale experiments on fire smoke movements in tunnels," Fire Safety Science, vol. 15, no. 4, pp. 212-218, 2006.

[7] P. Xu, S. Jiang, J. Zhou, D. Chen, and Y. Xie, "Experimental study on smoke temperature distribution in immersed tunnel fire scenarios," Modern Tunnelling Technology, vol. 52, no. 5, pp. 79-83, 2015.

[8] Q. Guo, Z. Yan, and H. Zhu, "Full-scale experimental study on smoke and temperature distribution characteristics of the tunnel fire at high altitude," China Civil Engineering Journal, vol. 8, pp. 114-120, 2017.

[9] G. Cao, S. Jiang, J. Zhou, S. Liu, and J. Chen, "Research on flow behavior of fumes by lateral concentrated smoke exhaust of immersed tunnel," China Journal of Highway and Transport, vol. 31, no. 1, pp. 82-90, 2018.

[10] X. Chen, X. Shi, H. Wang, R. Zhu, and W. Jiang, "A study of fire extinguishing effect of low pressure water mist fire extinguishing system in tunnel fire," Building Science, vol. 34, no. 4, pp. 72-77, 2018.

[11] L. Yi, Y. Yang, Z. Xu, D. Wu, and W. Li, "Maximum temperature of smoke near vault in road tunnel fires with longitudinal ventilation," Journal of Combustion Science and Technology, vol. 17, no. 2, pp. 109-114, 2011.

[12] Z. Xu, G. Yang, D. Wu, and W. Li, "Research on temperature field smoke shaft corbel in extra-long tunnels," Journal of Railway Science and Engineering, vol. 7, no. 3, pp. 82-86, 2010.

[13] Y. Wu and M. Z. A. Bakar, "Control of smoke flow in tunnel fires using longitudinal ventilation systems - a study of the critical velocity," Fire Safety Journal, vol. 35, no. 4, pp. 363-390, 2000.

[14] Z. Yuan, B. Lei, and A. Kashef, "Reduced-scale experimental research on fires in tunnels with natural ventilation," Procedia Engineering, vol. 62, pp. 907-915, 2013.

[15] L. Xu and X. Zhang, "Rational determination of longitudinal control wind velocity for fire ventilation of horizontal tunnel," China Journal of Highway and Transport, vol. 20, no. 2, pp. 92-96, 2007.

[16] S. Gannouni and R. B. Maad, "Numerical study of the effect of blockage on critical velocity and backlayering length in longitudinally ventilated tunnel fires," Tunnelling and Underground Space Technology, vol. 48, pp. 147-155, 2015. 
[17] S. Gannouni and R. Ben Maad, "Numerical analysis of smoke dispersion against the wind in a tunnel fire," Journal of Wind Engineering and Industrial Aerodynamics, vol. 158, pp. 61-68, 2016.

[18] W. Wojciech and L. Tomasz, "Wind and fire coupled modelling-part I: literature review," Fire Technology, vol. 54, no. 5, pp. 1405-1442, 2018.

[19] W. Wegrzynski, T. Lipecki, and G. Krajewski, "Wind and fire coupled modelling-part II: good practice guidelines," Fire Technology, vol. 54, no. 5, pp. 1443-1485, 2018.

[20] S. Sun, Y. Zhang, P. Lei, and J. Wu, "Application conditions of froude criteria for fire model test of highway tunnel," China Journal of Highway and Transport, vol. 29, no. 5, pp. 103-108, 2016.

[21] M. Wang, Y. Qi-Xin, Y. Zeng, X. Yuan, and Z. Yang, "Study on network ventilation system in Qinling Zhongnanshan very long highway tunnel under fire model," Underground Space, vol. 22, no. 1, pp. 65-71, 2002.

[22] Y. Zeng, Y. Li, C. He, and B. Guan, "Tunnel ventilation network calculation," Journal of Southwest Jiaotong University, vol. 2, pp. 183-187, 2003.

[23] Y. Zeng and C. He, "Research on rescue ventilation in highway tunnel with air exchange shaft," Journal of Disaster Prevention and Mitigation Engineering, vol. 29, no. 2, pp. 219-223, 2009.

[24] Y. Zeng and C. He, "The research of ventilation scheme with shaft in submarine shield tunnel," Chinese Journal of Underground Space and Engineering, vol. 5, no. 6, pp. 1220-1226, 2009.

[25] F. Tarada, "Critical velocities for smoke control in tunnel cross-passages," in Proceedings of the First International Conference on Major Tunnel and Infrastructure Projects, pp. 22-24, Taiwan, China, 2000.

[26] Y. Li and B. Lei, "Model of critical velocity in a tunnel crosspassage," Journal of the China Railway Society, vol. 30, no. 3, pp. 87-90, 2008.

[27] Y. Z. Li, B. Lei, and H. Ingason, "Theoretical and experimental study of critical velocity for smoke control in a tunnel crosspassage," Fire Technology, vol. 49, no. 2, pp. 435-449, 2013.

[28] Y.-s. Hou, Y.-f. Li, and C. Zhang, "Influence of train location on smoke control in tunnel cross-passage," Procedia Engineering, vol. 135, pp. 567-573, 2016.

[29] X. Jiang, J. Zhang, C. He, and J. Wang, "Study on critical wind velocity of cross passage in railway tunnel," China Railway Science, vol. 38, no. 4, pp. 55-61, 2017.

[30] S. Wang, Z. Lin, and S. Yu, "The characteristic and damage of fire accidents in road tunnel," Fire Science and Technology, vol. 30, no. 4, pp. 337-340, 2011.

[31] JTG/T D70/2-02-2014, Guidelines for Design of Ventilation of Highway Tunnel.

[32] L. Hu, Studies on Thermal Physics of Smoke Movement in Tunnel fires, University of Science and Technology of China, Anhui, Hefei, China, Doctor of Philosophy, 2006.

[33] K. Lai, Simulate Research on the Equivalent Resistance of Grid Used to Tunnel Ventilation Model Test. Master, Chang'an University, Xi'an, China, 2015.

[34] K. McGrattan, S. Hostikka, R. McDermott, J. Floyd, C. Weinschenk, and K. Overholt, Fire Dynamics Simulator (Version 6), Technical Reference Guide, National Institute of Standards and Technology (NIST), Gaithersburg, MD, USA, 2014. 